\title{
Modelling Sorption and Leaching Behaviour of Sulphate in Light Sierozem (Calcids) Columns with Rape Straw Biochar Amendments with Steady Flow
}

\author{
B. W. Zhao $†$, X. J. Nan, Y. Q. Li, H. Liu and K. X. Duan \\ School of Environmental and Municipal Engineering, Lanzhou Jiaotong University, No. 88, West Anning Rd., \\ Lanzhou 730070, P. R. China \\ †Corresponding author: Baowei Zhao; zhbw2001@sina.com
}

Nat. Env. \& Poll. Tech.

Website: www.neptjournal.com

Received: 07-02-2020

Revised: $22-02-2020$

Accepted: 02-05-2020

Key Words:

Biochar

Sorption

Leaching

Light sierozem

Modelling

\begin{abstract}
Biochar amendments could enhance retention of nutrients such as ammonium $\left(\mathrm{NH}_{4}^{+}\right)$, nitrate $\left(\mathrm{NO}_{3}^{-}\right)$, and phosphate $\left(\mathrm{PO}_{4}^{3-}\right)$ in soils. However, the situation for sulphate $\left(\mathrm{SO}_{4}^{2-}\right)$, which is an indispensable nutrient element for crop growth, is unclear. In this paper, the effects of biochar derived from rape (Brassica campesstris L.) straw at $600^{\circ} \mathrm{C}$ on the sorption and leaching of $\mathrm{SO}_{4}^{2-}$ in light sierozem (Calcids) was studied in columns, where biochar amendment rate, column soil height, solution pH value and initial sulphate concentration were selected as factors. It is shown that the transport of sulphate was a significant non-equilibrium process and the sorption and leaching curves (SLCs) of sulphate were asymmetrical. The breakthrough time would be increased by increasing biochar amendment and soil column height, and by decreasing solution $\mathrm{pH}$ value and initial sulphate concentration. The SLCs of bromide trace were fitted to determine dispersion coefficient $(D)$ using equilibrium convection dispersion equation $\left(C D E_{e q}\right)$. The non-equilibrium (two-site) model $\left(C D E_{n o n-e q}\right)$ with the results from $\mathrm{CDE}_{\mathrm{eq}}$ was used to simulate the transport processes of sulphate in the soil column, with good fitness, using software CXTFIT 2.1 fitting. The results could supply an implication for biochar application in loess areas.
\end{abstract}

\section{INTRODUCTION}

Sulphur is an indispensable nutrient element for crop growth (Frossard et al. 2012). It is a protein and amino acid constituent element, acts as an enzymatic reactive centre and is an important medium for chlorophyll, sitosterone, glutathione and coenzyme syntheses. Although sulphur is not a structural element of plant cells, it plays an important role in plant growth regulation, detoxification, defence and resistance, and quality of plant (Frossard et al. 2012). Therefore, the migration and conversion of sulphur in soils have been paid more and more attention (Blum et al. 2013, Matusik 2014).

Biochar is the product derived from biomass pyrolysis under limited oxygen conditions. Biochar can be used as a soil amendment to improve soil quality and to increase crop production. The indirect nutrient value of biochar is its ability to retain nutrients in the soil and thus to reduce nutrient leaching losses, resulting in increased nutrient uptake by plants and crop production (Lehmann \& Joseph 2009). Recently, many reports showed that when biochars were added into soils, the nutrient ions $\left(\mathrm{NH}_{4}^{+}, \mathrm{NO}_{3}{ }^{-}\right.$and $\mathrm{PO}_{4}^{3-}$ ) in soils were retained, the nitrogen and phosphorus leaching losses in soils were reduced, and plant uptake of these nutrients was improved (Saarnio et al. 2013, Zheng et al. 2013, Soinne et al. 2014, Mandal et al. 2016, Zhang et al. 2016). However, to our knowledge, few reports on the effect of biochar on sulphur fate (e.g. sorption and leaching) in soil have appeared in the literature (Zhao et al. 2017).

The solute transport in porous media is a complex physical and chemical process (Marín-Benito et al. 2013, Jing et al. 2014). To date, a few soil column experiments have been conducted to investigate the retention and leaching of ammonium $\left(\mathrm{NH}_{4}^{+}\right)$, nitrate $\left(\mathrm{NO}_{3}^{-}\right)$, and phosphate $\left(\mathrm{PO}_{4}^{3-}\right)$ ions in the presence of biochars (Laird et al. 2010, Yao et al. 2012, Jing et al. 2014, Kanthle et al. 2016, Pratiwi et al. 2016, Xu et al. 2016, Feng et al. 2017, Lou et al. 2017, Joseph et al. 2018, Shi et al. 2020). However, no predicting or modelling for nutrient migration is found in these researches. The nonequilibrium convection dispersion equation $\left(\mathrm{CDE}_{\text {non-eq }}\right)$ is often used to describe the process of reactive solute transport in soil. $\mathrm{CDE}_{\text {non-eq }}$ can be grouped into two categories, i.e. Two-region Model (TRM) and Two-site Model (TSM) (Huo et al. 2013, Srinivasan \& Sarmah 2014). As stagnant water and slow reaction are concerned in these models, the sorption and leaching of solute can be described more accurately. However, up to date, there have been few applications of 
these models to describe the nutrient migration in soils in the present of biochars.

Loess soils (e.g. light sierozem (Calcids)) have high porosity and permeability, low organic matter content and loosely packed particles. It seems that biochar should be added into loess soils to improve retention of nutrients (e.g. sulphur) and crop growth. Thus, in this paper, the column experiments were conducted to investigate the sorption and leaching of sulphate in light sierozem (Calcids) with the amendment of rape straw biochar. The main objectives of this experiment were to (i) evaluate the effects of biochar amendment rate, column soil height, solution $\mathrm{pH}$ value and initial sulphate concentration on the sorption and leaching of $\mathrm{SO}_{4}{ }^{2-}$; and (ii) model the sorption and leaching processes of sulphate in light sierozem columns with $\mathrm{CDE}_{\text {non-eq }}$ using software CXTFIT 2.1 fitting.

\section{MATERIALS AND METHODS}

\section{Chemicals and Materials}

Analytical grade sodium sulphate and potassium bromide with spectral purity were purchased from Shanghai Chemical Co., China. Deionized water was used in all the experiments.

Rape (Brassica campesstris L.) straw was collected from Baiyin, Gansu, China. The feedstock was washed with tap water, air-dried, ground using a grinder and passed through a $0.43 \mathrm{~mm}$ sieve. This $<0.43 \mathrm{~mm}$ fraction was placed in crucibles and heated in a muffle furnace at $600^{\circ} \mathrm{C}$ for $6 \mathrm{~h}$ to pyrolyze the biomass. The obtained samples were washed with $1 \mathrm{~mol} \cdot \mathrm{L}^{-1} \mathrm{HCl} 4$ times, washed with deionized water several times and then dried in an oven at $80^{\circ} \mathrm{C}$. The prepared biochar was labelled as BS600. The basic properties of the biochar are as follows: pH 5.36; BET specific area $157.5 \mathrm{~m}^{2} \cdot \mathrm{g}^{-1}$; element composition, C $80.51 \%, \mathrm{H} 1.85 \%, \mathrm{~N}$ $1.17 \%, \mathrm{O} 15.79 \%$ and $\mathrm{S} 0.68 \%$; atomic ratios, $(\mathrm{N}+\mathrm{O}) / \mathrm{C}$ $0.21, \mathrm{H} / \mathrm{C} 0.02$.

The soil to be tested was collected from a rural farm field of light sierozem in Yuzhong County, Lanzhou, China; stones and other debris were picked out, and the soil was left to dry naturally. Then, the soil was thoroughly mixed and passed through a 20-mesh sieve. The basic physicochemical properties of the soil are as follows: $\mathrm{pH} 7.97$; organic matter content 14.12 g. $\mathrm{kg}^{-1}$; cation exchange capacity (CEC) 5.65 cmol.kg ${ }^{-1}$; efficient sulphur 36.7 mg.kg ${ }^{-1}$.

\section{Column Sorption and Leaching}

The glass column was $2.5 \mathrm{~cm}$ in diameter. At the bottom of the column, there was a sheet of cotton and a quartz sand layer approximately $1.5 \mathrm{~cm}$ in height, which should prevent the elution of soil fines. The column was packed with soil or the mixture of soil and BS600. After the column was filled, a quartz sand layer was placed upon it to obtain the uniform distribution of solution at the surface. The column was firstly saturated with water. Then, at a steady flow state $\left(v=7.64 \mathrm{~cm} . \mathrm{h}^{-1}\right), \mathrm{Br}^{-}\left(0.05 \mathrm{~mol} . \mathrm{L}^{-1}\right)$ or $\mathrm{SO}_{4}{ }^{2-}$ solution was input using a peristaltic pump until a constant concentration of solute in the effluent was obtained. Then, distilled water was pumped into the column to facilitate leaching. The effluent was collected at each 0.1 pore volume (PV) interval. The $\mathrm{Br}^{-}$concentration in the effluent was analysed using the ion-selective electrode method, and $\mathrm{SO}_{4}{ }^{2-}$ was analysed using barium chromate indirect atomic absorption spectrometry (AAS) (Ni et al. 2012). The BS600 amendment rate $(0 \%$, $5 \%, 10 \%$ and $15 \%)$, height of soil column $(5,10,15$ and $20 \mathrm{~cm})$, solution $\mathrm{pH}$ value $\left(3,5,7\right.$ and 9) and initial $\mathrm{SO}_{4}{ }^{2-}$ concentration $\left(50,100,150\right.$, and $\left.200 \mathrm{mg} . \mathrm{L}^{-1}\right)$ were kept as $5 \%, 10 \mathrm{~cm}, 7$ and $50 \mathrm{mg} . \mathrm{L}^{-1}$, respectively, except that they were tested as influencing factors. The bulk density ( ) of the packed columns was determined as 1.14, 0.93, 0.83 and 0.75 g.cm ${ }^{-3}$ with the BS600 amendment rate at $0 \%, 5 \%, 10 \%$ and $15 \%$, respectively.

\section{Solute Transport Modeling}

The equilibrium convection dispersion equation $\left(\mathrm{CDE}_{\mathrm{eq}}\right)$ (1) was used to describe the one-dimensional homogeneous transport of nonreactive solute $\mathrm{Br}^{-}$in the soil without or with BS600 (Pang \& Close 1999, Fan et al. 2011):

$$
R \frac{\partial C}{\partial t}=D \frac{\partial^{2} C}{\partial x^{2}}-v \frac{\partial C}{\partial x}
$$

Where, $C$ is the solute concentration $\left(\mathrm{mg} . \mathrm{L}^{-1}\right) ; t$ is time (h); $x$ is the vertical distance $(\mathrm{cm}) ; D$ is the dispersion coefficient $\left(\mathrm{cm}^{2} \cdot \mathrm{h}^{-1}\right)$, and $v$ is the average pore water velocity $\left(\mathrm{cm} \cdot \mathrm{h}^{-1}\right)$. The following initial and boundary conditions are assumed for $\mathrm{Br}^{-}$transport in a column (Shao et al. 1998, Pang \& Close 1999, Inoue et al. 2000, Kamra et al. 2001, Fan et al. 2011):

$$
\begin{gathered}
C(x, 0)=0 \\
C(0, t)=C_{0} \\
{\left.\left[-D \frac{\partial C}{\partial x}+v C\right]\right|_{x=0^{+}}=v C_{0}}
\end{gathered}
$$

Where, $C_{0}$ is the initial concentration of solute $\left(\mathrm{mg} \cdot \mathrm{L}^{-1}\right)$. Parameter $D$ was calculated from the fitting of the sorption and leaching curve (SLC) for nonreactive solute $\mathrm{Br}^{-}$using CXTFIT 2.1, where the value of the retardation coefficient (dimensionless) $(R)$ was set to 1 because it is assumed that bromide ions have minimal sorption onto soil particles (Fan et al. 2011). The obtained $D$ parameters were later used as input for modelling sulphate transport. 
Two-site Model (TSM) and Two-region Model (TRM) can be put into the same dimensionless form when considering the description of linear sorption and steady flow (Huo et al. 2013, Srinivasan \& Sarmah 2014). If dimensionless parameters are used, the $\mathrm{CDE}_{\text {non-eq }}$ for solute transport is described as:

$$
\begin{gathered}
\beta R \frac{\partial C_{1}}{\partial T}=\frac{1}{P} \frac{\partial^{2} C_{1}}{\partial Z^{2}}-\frac{\partial C_{1}}{\partial Z}-\omega\left(C_{1}-C_{2}\right) \\
(1-\beta) R \frac{\partial C_{2}}{\partial T}=\omega\left(C_{1}-C_{2}\right) \\
f=\frac{\beta R-1}{R-1} \\
a=\frac{\omega V}{(1-\beta) R L}
\end{gathered}
$$

Where the subscript 1 and 2 refer to equilibrium and non-equilibrium sorption sites; the retardation factor $R$ can be calculated directly from solution breakthrough curves; $\beta$ is the fraction factor (dimensionless); $a$ is the first-order mass transfer coefficient governing the rate of solute exchange between both phases $\left(\mathrm{h}^{-1}\right) ; f$ is the fraction of exchange sites assumed to be at equilibrium for the TSM; $\omega$ is the dimensionless mass transfer coefficient; $L$ is the length of the column $(\mathrm{cm})$; and the dimensionless parameters $T, Z$ and $P$ (peclet number) are defined as $T=V t / L, Z=x / L$ and $P=V L / D$, respectively. The degree of non-equilibrium can be directly evaluated with the $\beta$ and $\omega$ values. When the $\beta$ value equals to 1 , there is no physical non-equilibrium process for nonreactive solute or all the sorption sites are instantaneously occupied by a reactive solute (Pang \& Close 1999). When the $\beta$ value is less than 1 , the sorption of reactive solute is rate-limited, where high $\omega$ value indicates the fast sorption/ diffusion process occurs while low $\omega$ value indicates the slow sorption/diffusion process exists (Brusseau et al. 1989). In this paper, the results from $\mathrm{CDE}_{\mathrm{eq}}$ and the non-equilibrium (two-site) model was used to simulate the transport processes of sulphate in the soil column.

\section{RESULTS AND DISCUSSION}

\section{$\mathrm{Br}^{-}$SLCs}

Fig. 1 shows the sorption and leaching curves (SLCs) for transport $\left(v=7.64 \mathrm{~cm} \cdot \mathrm{h}^{-1} ; \mathrm{L}=10 \mathrm{~cm}, C_{\mathrm{o}}=0.05 \mathrm{~mol} . \mathrm{L}^{-1}\right.$ and $\mathrm{pH}=7$ ) of the nonreactive bromide ions $\left(\mathrm{Br}^{-}\right)$through columns with the BS600 addition rates of $0 \%, 5 \%, 10 \%$ and $15 \%$, respectively. Although the addition rates of BS600 were different, the SLCs were symmetrical without tailing. However, with the increase in the amount of biochar added, the PV also increased from 1.3 to 1.5 . In the present study no preferential flow of $\mathrm{Br}^{-}$was observed in any of the columns, as the maximum breakthrough for the bromide trace was similar on all occasions, and no significant tailing was observed in the $\mathrm{Br}^{-} \mathrm{SLCs}$, which is an indication of a well saturated soil column.

The SLCs of the nonreactive solute $\mathrm{Br}^{-}$were fitted with $\mathrm{CDE}_{\text {eq }}$ using CXTFIT 2.1, and the results are shown in Fig. 1 and listed in Table 1. All the modelled curves were well fitted the experimental data (Fig. 1), with no tailing
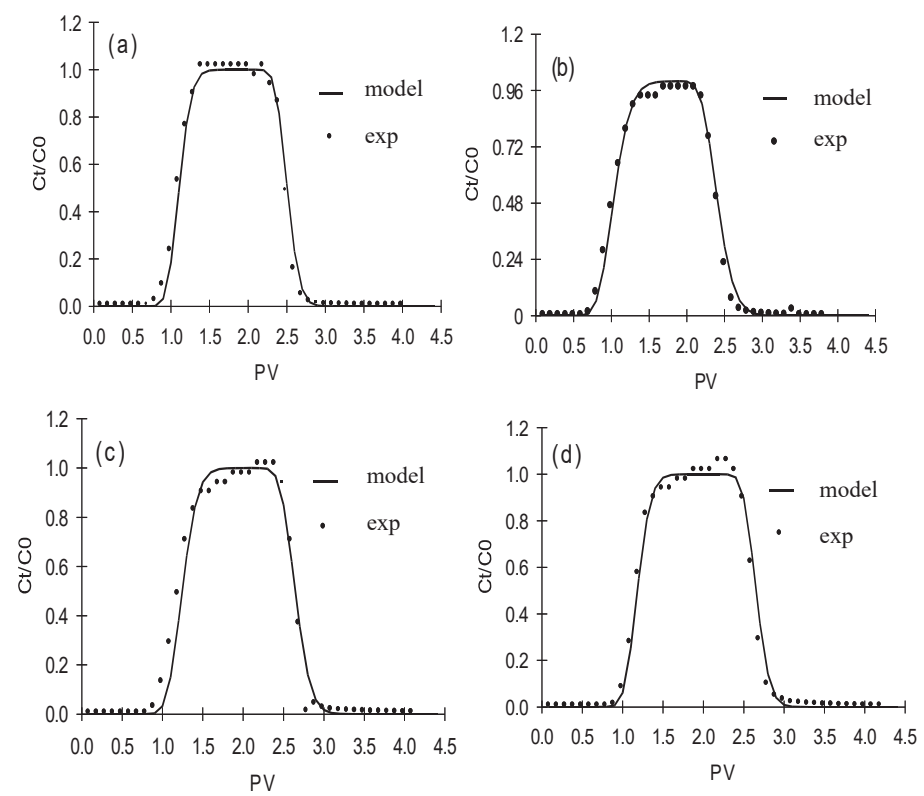

Fig. 1: Experimental and stimulated SLCs for $\mathrm{Br}^{-}$transport in columns with 0\% (a), 5\% (b), 10\% (c) and 15\% (d) BS600 amendment. 
Table 1: Fitted parameters using $\mathrm{CDE}_{\mathrm{eq}}$ for SLCs of $\mathrm{Br}^{-}$

\begin{tabular}{|llll|}
\hline BS600 addition $(\%)$ & $D\left(\mathrm{~cm}^{2} \cdot \mathrm{h}^{-1}\right)$ & $r^{2}$ & MSE \\
\hline 0 & 0.48 & 0.997 & 0.0005 \\
5 & 1.11 & 0.995 & 0.0008 \\
10 & 0.57 & 0.987 & 0.0025 \\
15 & 0.47 & 0.997 & 0.0006 \\
\hline
\end{tabular}

and asymmetry, indicating the absence of physical nonequilibrium conditions during the transport of $\mathrm{Br}$ - through the soil columns. The values of the regression coefficient $r^{2}$ and mean square error (MSE) are larger than 0.987 and less than 0.0025 respectively, indicating that $\mathrm{CDE}_{\mathrm{eq}}$ fits the transport of nonreactive solute $\mathrm{Br}^{-}$well. Meanwhile, the values of $D$ were obtained as $0.48,1.11,0.57$ and $0.47 \mathrm{~cm}^{2} \cdot \mathrm{h}^{-1}$, respectively.

\section{Effect of Biochar Amendment Rate}

Fig. 2 includes the experimental and stimulated SLCs corresponding to the $\mathrm{SO}_{4}{ }^{2-}$ transport in soil columns $(v=7.64$ $\mathrm{cm} \cdot \mathrm{h}^{-1} ; \mathrm{L}=10 \mathrm{~cm}, C_{\mathrm{o}}=50 \mathrm{mg} \cdot \mathrm{L}^{-1}$ and $\mathrm{pH}=7$ ) with $0,5 \%$, $10 \%$ and $15 \%$ BS600 addition. Four SLCs are asymmetrical and tailing, showing that BS600 is an important factor in $\mathrm{SO}_{4}{ }^{2-}$ transport in the columns. The breakthrough times were 1.6, 1.7, 1.9 and 2.1 PV for the columns with $0,5 \%, 10 \%$ and $15 \%$ BS600. The breakthrough time was delayed with the addition rate of BS600 increasing. These phenomena illustrate that the addition of high content of biochar could be beneficial to the retention of sulphate in the soil and reduction in the loss of sulphur. Besides, the breakthrough time in the
$\mathrm{SO}_{4}{ }^{2-}$ SLC with no BS600 addition shifted significantly by 1.3 to 1.6 compared with that of $\mathrm{Br}$ - with no BS600 addition (Fig. 1), which showed $\mathrm{SO}_{4}{ }^{2-}$ is a reactive solute to the soil. Moreover, with the addition rate of BS600 increasing from $5 \%$ to $15 \%, \mathrm{PVs}$ in the $\mathrm{SO}_{4}{ }^{2-}$ SLCs shifted by 1.7 to 2.1 . This indicates that biochar amendment changed further the sorption properties of soil and was indicative of the influence of the retardation. It can be deduced that the retardation is mainly due to the roles of sorption-related processes of sulphate onto soil or biochar-soil mixture. In our previous study (Zhao et al. 2017), sulphate sorption on BS600, soil and BS600-soil mixture was investigated by batch experiments. It was shown that sulphate was mainly sorbed onto BS600 through electrostatic interaction, whereas onto the soil via electrostatic interaction and formation of poorly soluble $\mathrm{CaSO}_{4}$. Shi et al. (2020) designed the column leaching experiment over 30 days to evaluate the effects of a granular biochar-mineral urea composite on cumulative $\mathrm{N}$ release and of dissolved organic carbon (DOC). Significant loss decrease of $\mathrm{NH}_{4}{ }^{+} \mathrm{N}$ and DOC by $>70 \%$ and by $8 \%$ was founded. Loss decrease of $\mathrm{NH}_{4}{ }^{+}-\mathrm{N}$ could be due to $\mathrm{NH}_{4}{ }^{+}$adsorption onto or by functional groups such as $-\mathrm{COO}^{-}(-\mathrm{COOH})$, amino and $-\mathrm{O}^{-}(-\mathrm{OH})$ on the biochar surfaces while that of DOC was attributed to the formation of organo-mineral micro-aggregates.

The SLCs of $\mathrm{SO}_{4}{ }^{2-}$ in columns with the different BS600 addition rates were fitted with $\mathrm{CDE}_{\text {non-eq }}$ and the results are shown in Fig. 2 and listed in Table 2. $\mathrm{CDE}_{\text {non-eq }}$ could fit
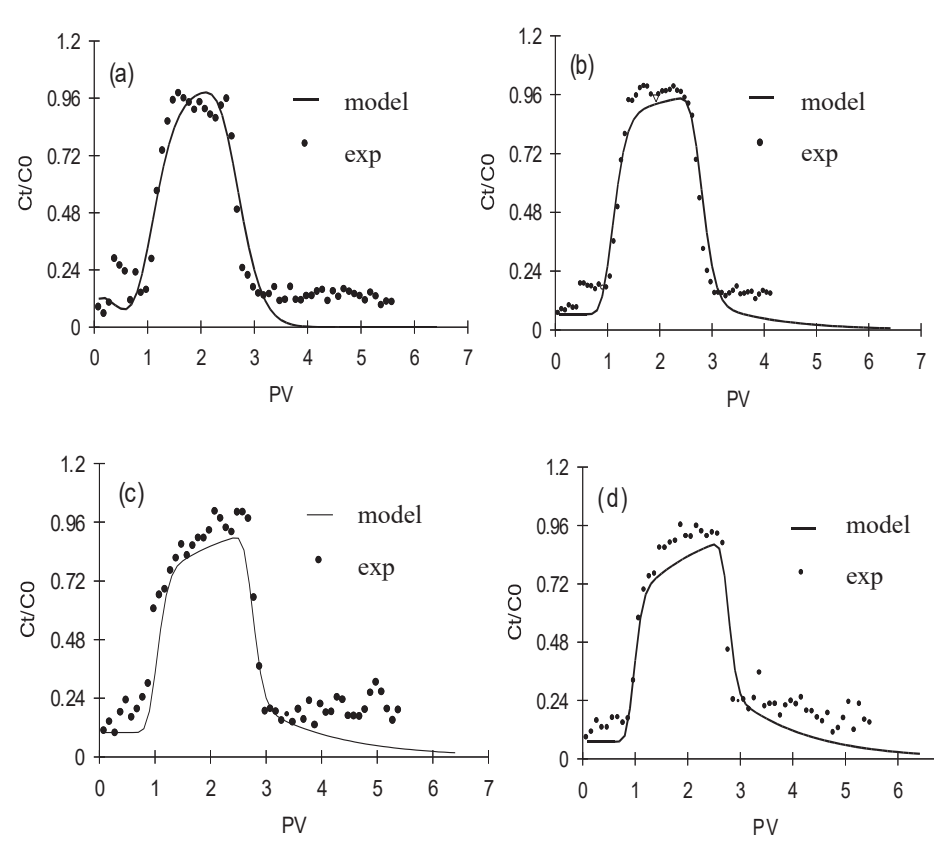

Fig. 2: Experimental and stimulated SLCs for $\mathrm{SO}_{4}{ }^{2-}$ transport in columns with $0 \%$ (a), $5 \%$ (b), $10 \%$ (c) and $15 \%$ (d) BS600 amendment. 
Table 2: Fitted parameters using $\mathrm{CDE}_{\text {non-eq }}$ for $\mathrm{SLCs}$ of $\mathrm{SO}_{4}^{2-}$ through different columns.

\begin{tabular}{|c|c|c|c|c|c|c|}
\hline Column & & $R$ & $\beta$ & $\omega$ & $r^{2}$ & $M S E$ \\
\hline \multirow[t]{4}{*}{ BS600 addition (\%) } & 0 & 1.47 & 0.85 & 0.32 & 0.98 & 0.0019 \\
\hline & 5 & 1.33 & 0.85 & 0.16 & 0.96 & 0.0061 \\
\hline & 10 & 1.53 & 0.82 & 0.21 & 0.99 & 0.0019 \\
\hline & 15 & 1.71 & 0.74 & 0.28 & 0.97 & 0.0033 \\
\hline \multirow[t]{4}{*}{ Column soil height $(\mathrm{cm})$} & 5 & 1.13 & 0.89 & 0.14 & 0.88 & 0.0010 \\
\hline & 10 & 1.33 & 0.85 & 0.16 & 0.96 & 0.0061 \\
\hline & 15 & 1.48 & 0.72 & 0.35 & 0.88 & 0.0013 \\
\hline & 20 & 1.50 & 0.69 & 0.45 & 0.93 & 0.0076 \\
\hline \multirow[t]{4}{*}{ Solution $\mathrm{pH}$ value } & 3 & 2.03 & 0.57 & 0.43 & 0.97 & 0.0027 \\
\hline & 5 & 1.69 & 0.65 & 0.40 & 0.95 & 0.0054 \\
\hline & 7 & 1.72 & 0.65 & 0.31 & 0.96 & 0.0040 \\
\hline & 9 & 1.59 & 0.63 & 0.40 & 0.95 & 0.0044 \\
\hline \multirow[t]{4}{*}{ Initial $\mathrm{SO}_{4}^{2-}$ concentration $\left(\mathrm{mg} \cdot \mathrm{L}^{-1}\right)$} & 50 & 1.46 & 0.69 & 0.14 & 0.96 & 0.0054 \\
\hline & 100 & 1.42 & 0.78 & 0.15 & 0.98 & 0.0032 \\
\hline & 150 & 1.33 & 0.92 & 0.19 & 0.96 & 0.0041 \\
\hline & 200 & 1.46 & 0.79 & 0.15 & 0.96 & 0.0054 \\
\hline
\end{tabular}

the transport of the reactive solute $\mathrm{SO}_{4}{ }^{2-}$ well $\left(r^{2} 0.96\right.$ and MSE 0.0061). The resultant $\beta$ values are $0.85,0.85,0.82$ and 0.74 , respectively, for the four column runs. These $\beta$ values are much lower than 1, indicating a part of the sorption sites did not participate in the instantaneous adsorption, i.e. $\mathrm{SO}_{4}{ }^{2-}$ adsorption was in the non-equilibrium state. In column tests, the transport, adsorption and desorption of solute are taking place in a dynamic system that is subject to the effects of hydrodynamic conditions. All the $R$ values are larger than 1 , which also indicated the sorption and leaching processes were non-equilibrium. Thus, the $\mathrm{CDE}_{\text {non-eq }}$ is more adequate for simulating $\mathrm{SO}_{4}{ }^{2-}$ transport in the soil or the soil with BS600 amendment. In other words, non-equilibrium sorption should be taken into account in simulating $\mathrm{SO}_{4}{ }^{2-}$ transport in the saturated loess.

\section{Effect of Column Soil Height}

Fig. 3 illustrates the experimental and stimulated SLCs corresponding to the sorption and leaching of $\mathrm{SO}_{4}{ }^{2-}$ in soil columns $\left(v=7.64 \mathrm{~cm} \cdot \mathrm{h}^{-1} ; C_{\mathrm{o}}=50 \mathrm{mg} \cdot \mathrm{L}^{-1}\right.$ and $\left.\mathrm{pH}=7\right)$ with $5,10,15$ and $20 \mathrm{~cm}$ of column soil height and 5\% BS600 content. The SLCs of $\mathrm{SO}_{4}{ }^{2-}$ through columns were all asymmetrical, indicating the interaction of $\mathrm{SO}_{4}{ }^{2-}$ with the soil to a greater extent with increasing column soil height. The phenomena in Fig. 3 (a) and (b) are not significant, but those in Fig. 3 (c) and (d) are significantly asymmetrical tailing. The breakthrough time of 1.6, 1.7, 1.9 and 2.0 PV for $\mathrm{SO}_{4}{ }^{2-}$ in Fig. 3 (a), (b), (c) and (d) were observed, respectively. With the increase in column soil height, the contact between soil or soil with biochar and $\mathrm{SO}_{4}{ }^{2-}$ increased. It seemed that the time-dependent interactions occurred between $\mathrm{SO}_{4}{ }^{2-}$ and the soil components (Brusseau et al. 1989). The previous study showed that dissolved nutrients $\left(\mathrm{NO}_{3}{ }^{-}\right.$and $\left.\mathrm{PO}_{4}{ }^{3-}\right)$ are first taken up into biochar pores along a concentration gradient and through capillary action, followed by surface sorption and retention processes which block biochar pores and result in deposition of a nutrient-rich organomineral (plaque) layer (Joseph et al. 2018).

The obtained parameters $R, \beta$ and $\omega$ from the SLCs fitting by CXTFIT 2.1 using CDE $_{\text {non-eq }}$ approach are listed in Table $2\left(r^{2} \quad 0.88, M E S \quad 0.0076\right)$. All the retardation coefficient $R$ values are larger than 1 and increased with column soil height increasing. The values of $\beta$ and $\omega$ further indicates that the system was under non-equilibrium conditions at the selected flow rates. The values of $\omega$ change from 0.14 to 0.45 and the values of $\beta$ is less than 1 , indicating there is some fraction of immobile water or rate-limited sorption sites.

\section{Effect of Initial Solution pH}

Fig. 4 shows the experimental and stimulated SLCs that corresponding to the $\mathrm{SO}_{4}{ }^{2-}$ transport $\left(v=7.64 \mathrm{~cm} \cdot \mathrm{h}^{-1} ; \mathrm{L}=10\right.$ $\mathrm{cm}$, and $C_{\mathrm{o}}=50 \mathrm{mg} . \mathrm{L}^{-1}$ ) in soil columns with 5\% BS600 amendment rate and with different $\mathrm{pH}$ values of the initial solutions. The SLCs are asymmetrical and tailing. PV decreased from 2.0 to 1.6 when the initial $\mathrm{pH}$ values rose from 3 to 9 . This could be attributed to the effects of $\mathrm{pH}$ values on the adsorption capacity of adsorbents. It has been reported that the sorbed amount of $\mathrm{SO}_{4}{ }^{2-}$ on the soil, $\mathrm{BS} 600$, and BS600-soil decreased as the solution $\mathrm{pH}$ values increased from 2 to 12 (Zhao et al. 2017). The variation of sorbed 

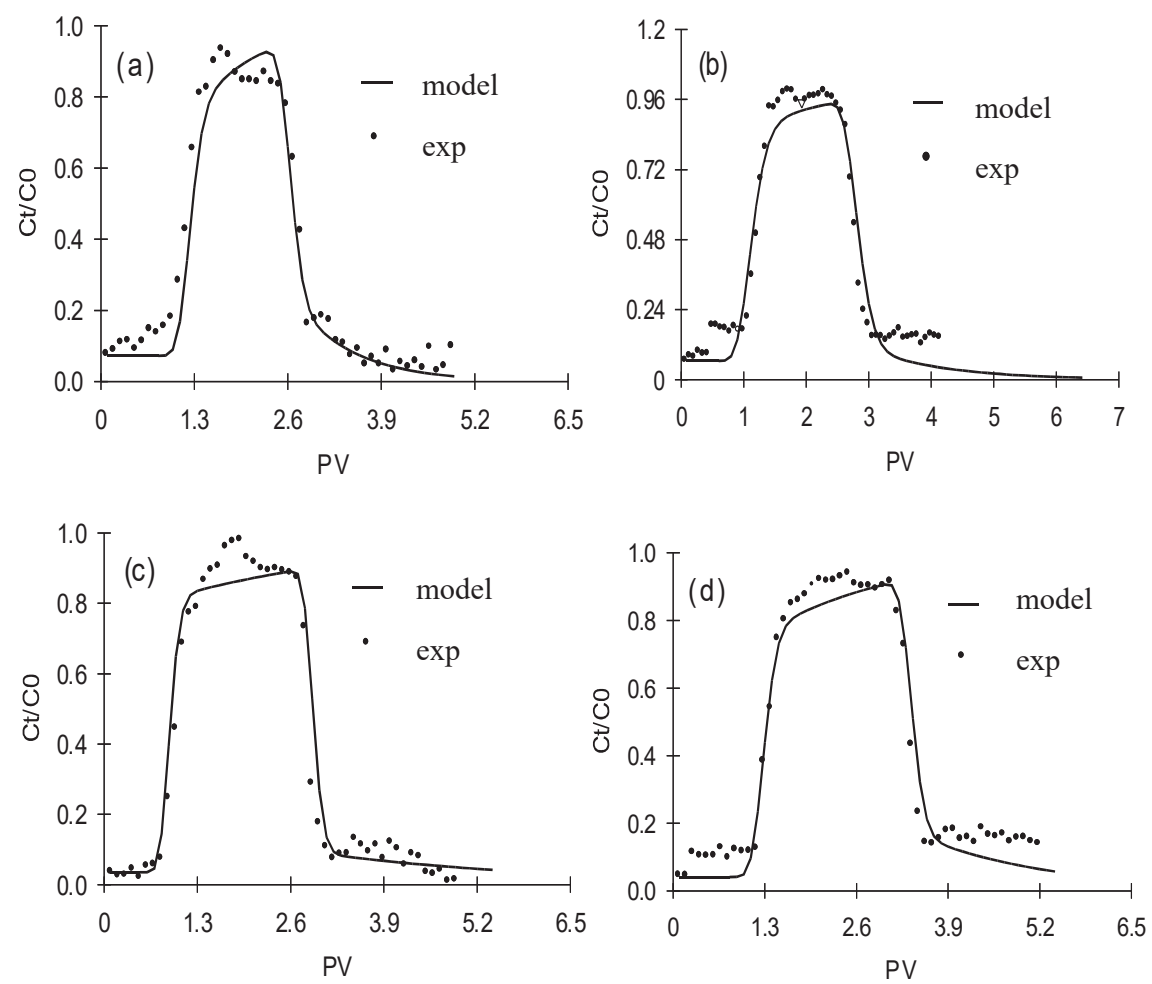

Fig. 3: Experimental and stimulated SLCs for $\mathrm{SO}_{4}{ }^{2-}$ transport in columns in 5 (a), 10 (b), 15 (c) and $20 \mathrm{~cm}$ (d) height.
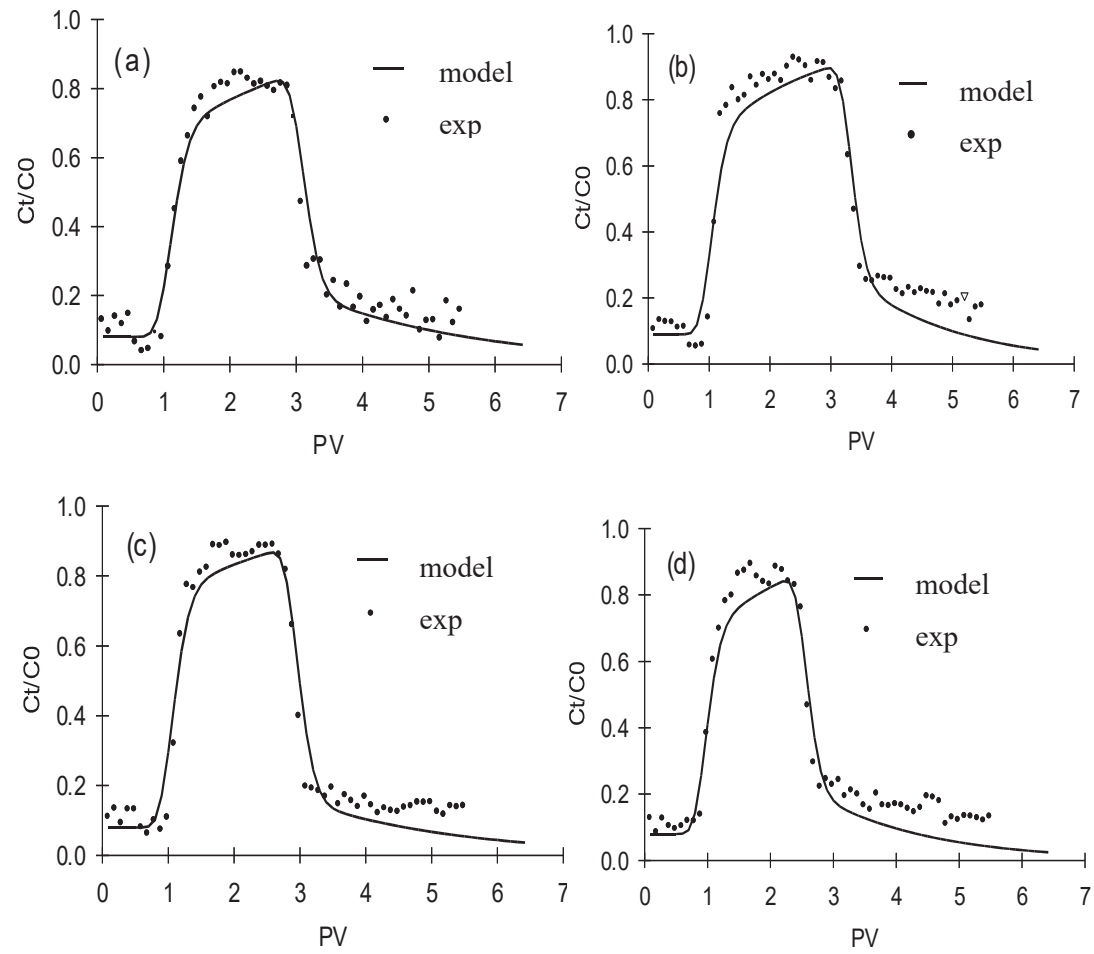

Fig. 4: Experimental and stimulated SLCs for $\mathrm{SO}_{4}{ }^{2-}$ transport in columns with 3 (a), 5 (b), 7 (c) and 9 (d) of solution pH value. 
amount of $\mathrm{SO}_{4}{ }^{2-}$ with $\mathrm{pH}$ values might be due to changes in the electrostatic interactions between $\mathrm{SO}_{4}{ }^{2-}$ and the charged sorbent surfaces. At higher $\mathrm{pH}$ values, the soil and biochar surfaces were more negatively charged, and therefore, the sorbed amount of $\mathrm{SO}_{4}{ }^{2-}$ decreased. Moreover, $\mathrm{OH}^{-}$competed with $\mathrm{SO}_{4}{ }^{2-}$ onto the sorbent surface sites, which also led to a decrease in the sorbed amount of $\mathrm{SO}_{4}{ }^{2-}$ (Zhao et al. 2017).

The fitted parameters for $\mathrm{SO}_{4}{ }^{2-}$ SLCs using $\mathrm{CDE}_{\text {non-eq }}$ models by CXTFIT 2.1 are also listed in Table 2. $\mathrm{CDE}_{\text {non-eq }}$ could fit the transport of the reactive solute $\mathrm{SO}_{4}{ }^{2-}$ well $\left(r^{2} 0.95\right.$ and MSE 0.0054). When the initial solution $\mathrm{pH}$ values were 3, 5, 7 and 9, the values of $R$ were 2.03, 1.69, 1.72 and 1.59, respectively, indicating the adsorption capacity of $\mathrm{SO}_{4}{ }^{2-} \mathrm{de}-$ creased at large as the $\mathrm{pH}$ increased. Lou et al. also found that an increase in the retardation coefficient $R$ causes an increase in the adsorption capacity (Lou et al. 2005). However, the values $\beta$ and $\omega$ have no significant difference.

\section{Effect of Initial $\mathrm{SO}_{4}^{2-}$ Concentration}

Fig. 5 illustrates the experimental and stimulated SLCs corresponding to the sorption and leaching of $\mathrm{SO}_{4}{ }^{2-}$ in soil columns $\left(v=7.64 \mathrm{~cm} \cdot \mathrm{h}^{-1} ; \mathrm{L}=10 \mathrm{~cm}\right.$ and $\left.\mathrm{pH}=7\right)$ with 50 , 100,150 and $200 \mathrm{mg} . \mathrm{L}^{-1}$ of initial $\mathrm{SO}_{4}{ }^{2-}$ concentrations and
5\% BS600 amendment. The breakthrough times were 1.7, 1.6, 1.6 and 1.4 PV when initial concentrations were 50, 100,150 and $200 \mathrm{mg} . \mathrm{L}^{-1}$, respectively. This also shows that an increase in the initial concentrations of solutions led to less breakthrough time. It was shown in our previous study (Zhao et al. 2017), that the maximum sorption capacities of BS600, BS600-soil mixture and the soil for $\mathrm{SO}_{4}{ }^{2-}$ were 19.57, 26.81, and $28.63 \mathrm{mg} . \mathrm{g}^{-1}$, respectively. Higher concentration gradients of $\mathrm{SO}_{4}{ }^{2-}$ in the systems would lead to a higher occupation rate of the reactive sorption sites (Takaya et al. 2016) and then less breakthrough time.

As seen in Table 2, $\mathrm{CDE}_{\text {non-eq }}$ could fit the transport of the reactive solute $\mathrm{SO}_{4}^{2-}$ well $\left(r^{2} \quad 0.96\right.$, MES $\left.\quad 0.0054\right)$. The change in initial concentrations of sulphate did not result in a significant change in $R, \beta$ and $\omega$ values.

\section{CONCLUSION}

The sorption and leaching of sulphate through soil columns with or without BS600 amendment was a significant non-equilibrium process and the sorption and leaching curves (SLCs) of sulphate were asymmetrical and tailing. Increasing biochar amendment and column height would lead to a
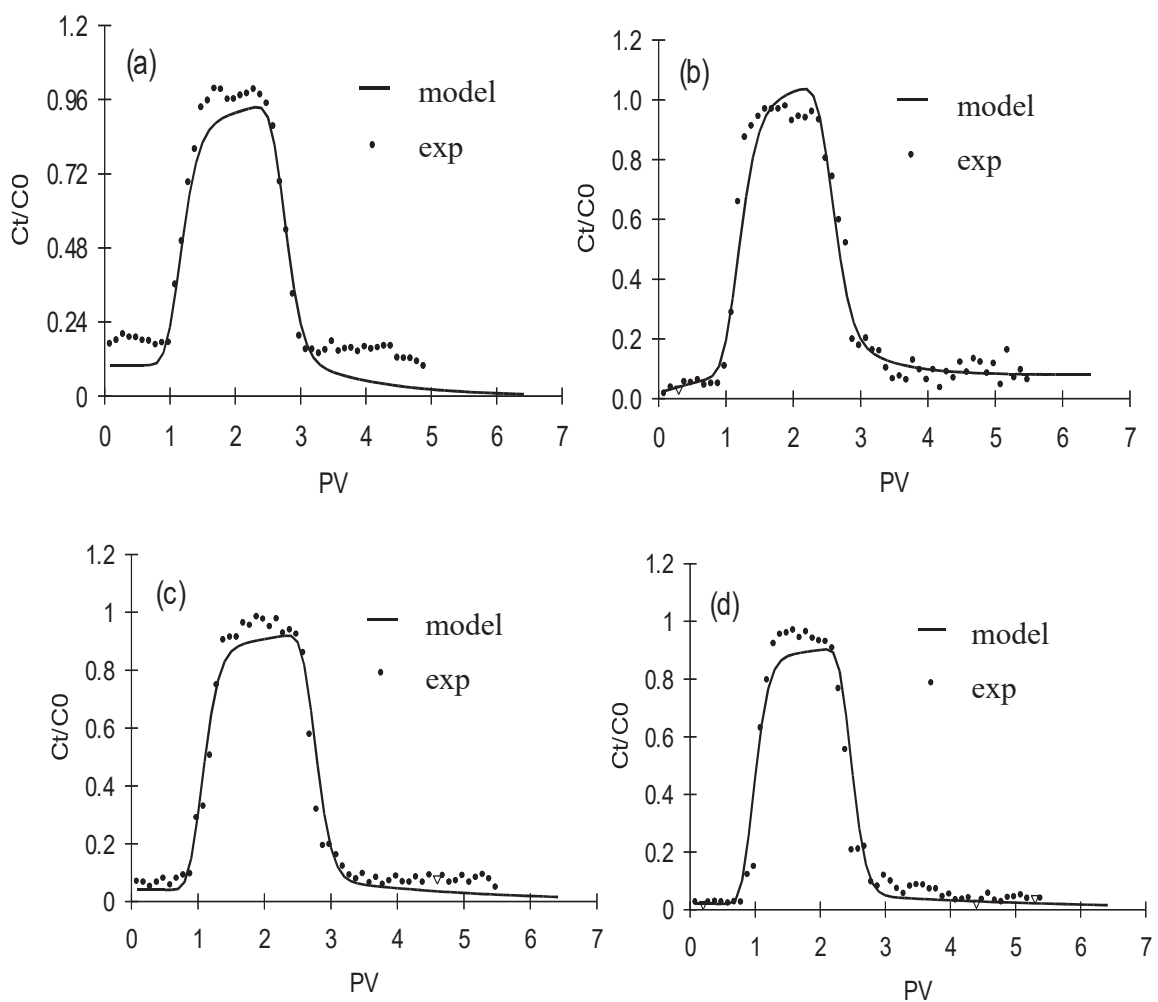

Fig. 5: Experimental and stimulated SLCs for $\mathrm{SO}_{4}^{2-}$ transport in columns with 50 (a), 100 (b), 150 (c) and 200 mg.L $\mathrm{L}^{-1}$ (d) of initial SO${ }_{4}^{2-}$ concentration. 
delaying breakthrough time and much sulphate retention. Meanwhile, decreasing solution $\mathrm{pH}$ value and initial sulphate concentration also enhanced the retention effect. The non-equilibrium convection dispersion equation $\left(\mathrm{CDE}_{\text {non-eq }}\right)$ could be used to fit the sorption and leaching behaviour of sulphate well, using software CXTFIT 2.1 fitting.

\section{ACKNOWLEDGEMENT}

This work was financially supported by the National Natural Science Foundation of China (51766008, 21467013, 21167007).

\section{REFERENCES}

Blum, S. C., Lehmann, J., Solomon, D., Caires, E. F., Reynaldo, L. and Alleoni, F. 2013. Sulphur forms in organic substrates affecting S mineralization in soil. Geoderma, 200: 156-164.

Brusseau, M. L., Rao, P. S. C., Jessup, R. E. and Davidson, J. M. 1989. Flow interruption: A method for investigating sorption nonequilibrium. J. Contam. Hydrol., 4: 223-240.

Fan, Z. S., Casey, F. X. M., Hakk, H., Larsen, G. L. and Khan, E. 2011. Sorption, fate, and mobility of sulfonamides in soils. Water Air Soil Pollut., 218: 49-61.

Feng, Y., Lu, H., Liu, Y., Xue, L., Dionysiou, D. D., Yang, L. and Xing, B. 2017. Nano-cerium oxide functionalized biochar for phosphate retention: preparation, optimization and rice paddy application. Chemosphere, 185: 816-825.

Frossard, E., Bünemann, E. K., Oberson, A. and Kertesz, M. A. 2012. Phosphorus and Sulphur in Soil. CRC Press, pp. 26.2-26.15.

Huo, L., Qian, T., Hao, J. and Zhao, D. 2013. Sorption and retardation of strontium in saturated Chinese loess: experimental results and model analysis. J. Environ. Radioactiv., 116: 19-27.

Inoue, M., Simunek, J., Shiozawa, S. and Hopmans, J. W. 2000. Simultaneous estimation of soil hydraulic and solute transport parameters from transient infiltration experiments. Adv. Water Resour., 23: 677-688.

Jing, Y., Chen, X., Li, Q., Jin, Z., Huang, Q., Zhang, J., Chen, C. and Lu, S. 2014. Effects of biochar application on the vertical transport of $\mathrm{NO}_{3}{ }^{-} \mathrm{N}$ in the red soil and its simulation. Chinese J. App. Ecol., 25: 3161-3167.

Joseph, S., Kammann, C. I., Shepherd, J. G., Conte, P., Schmidt, H.P., Hagemann, N., Rich, A. M., Marjo, C. E., Allen, J., Munroe, P., Mitchell, D. R. G., Donne, S., Spokas, K. and Graber, E. R. 2018. Microstructural and associated chemical changes during the composting of a high temperature biochar: Mechanisms for nitrate, phosphate and other nutrient retention and release. Sci. Total Environ., 618: 1210-1223.

Kamra, S. K., Lennartz, B., Genuchten, M. and Widmoser, P. 2001. Evaluating non-equilibrium solute transport in small soil columns. J. Contam. Hydrol., 48: 189-212.

Kanthle, A. K., Lenka, N. K., Lenka, S. and Tedia, K. 2016. Biochar impact on nitrate leaching as influenced by native soil organic carbon in an Inceptisol of central India. Soil Tillage Res., 157: 65-72.

Laird, D., Fleming, P., Wang, B., Horton, R and Karlen, D. 2010. Biochar impact on nutrient leaching from a Midwestern agricultural soil. Geoderma, 158: 436-442.
Lehmann, J. and Joseph, S. 2009. Biochar for Environmental Management: Science and Technology, Earthscan.

Lou, Y., Zhang, Y. and Lin, X. 2005. Effect of forms of nitrogen fertilizer on the bioavailability of heavy metals in the soils amended with biosolids and their uptake by corn plant. J. Zhejiang Univ., 31: 392-388.

Lou, Z., Sun, Y., Bian, S., Baig, S. A., Hu, B. and Xu, X. 2017. Nutrient conservation during spent mushroom compost application using spent mushroom substrate derived biochar. Chemosphere, 169: 23-31.

Mandal, S., Thangarajan, R., Bolan, N. S., Sarkar, B., Khan, N., Ok, Y. S. and Naidu, R. 2016. Biochar-induced concomitant decrease in ammonia volatilization and increase in nitrogen use efficiency by wheat. Chemosphere, 142: 120-127.

Marín-Benito, J. M., Brown, C. D., Herrero-Hernández, E., Arienzo, M., Sánchez-Martín, M. J. and Rodríguez-Cruz, M. S. 2013. Use of raw or incubated organic wastes as amendments in reducing pesticide leaching through soil columns. Sci. Total Environ., 463-464: 589-599.

Matusik, J. 2014. Arsenate, orthophosphate, sulphate, and nitrate sorption equilibria and kinetics for halloysite and kaolinites with an induced positive charge. Chem. Eng. J., 246: 244-253.

Ni, Z., Tang, F., Qu, M. and Mo, R. 2012. Determination of effective sulphur in soil by indirect AAS. Chinese J. Soil Sci., 43: 1136-1138.

Pang, L. and Close, M. E. 1999. Non-equilibrium transport of Cd in alluvial gravels. J. Contam. Hydrol., 36: 185-206.

Pratiwi, E. P. A., Hillary, A. K., Fukuda, T. and Shinogi, Y. 2016. The effects of rice husk char on ammonium, nitrate and phosphate retention and leaching in loamy soil. Geoderma, 277: 61-68.

Saarnio, S., Heimonen, K. and Kettunen, R. 2013. Biochar addition indirectly affects $\mathrm{N}_{2} \mathrm{O}$ emissions via soil moisture and plant $\mathrm{N}$ uptake. Soil Biol. Biochem., 58: 99-106.

Shao, M., Horton, R. and Miller, R. K. 1998. An approximate solution to the convection-dispersion equation of solute transport in soil. Soil Sci., 163: 339-345.

Shi, W., Ju, Y., Bian, R., Li, L., Joseph, S., Mitchell, D. R. G., Munroe, P., Taherymoosavi, S. and Pan, G. 2020. Biochar bound urea boosts plant growth and reduces nitrogen leaching. Sci. Total Environ., 701: 134424.

Soinne, H., Hovi, J., Tammeorg, P. and Turtola, E. 2014. Effect of biochar on phosphorus sorption and clay soil aggregate stability. Geoderma, 219-220: 162-167.

Srinivasan, P. and Sarmah, A. K. 2014. Assessing the sorption and leaching behaviour of three sulfonamides in pasture soils through batch and column studies. Sci. Total Environ., 493: 535-543.

Takaya, C. A., Fletcher, L. A., Singh, S., Anyikude, K. U. and Ross, A. B. Phosphate and ammonium sorption capacity of biochar and hydrochar from different wastes. Chemosphere, 145: 518-527.

Xu, N., Tan, G., Wang, H. and Gai, X. 2016. Effect of biochar additions to soil on nitrogen leaching, microbial biomass and bacterial community structure. Eur. J. Soil Biol., 74: 1-8.

Yao, Y., Gao, B., Zhang, M., Inyang, M. and Zimmerman, A. R. 2012. Effect of biochar amendment on sorption and leaching of nitrate, ammonium, and phosphate in a sandy soil. Chemosphere, 89: 1467-1471.

Zhang, H., Chen, C., Gray, E. M., Boyd, S. E., Yang, H. and Zhang, D. 2016. Roles of biochar in improving phosphorus availability in soils: A phosphate adsorbent and a source of available phosphorus. Geoderma, 276: 1-6.

Zhao, B., Nan, X., Xu, H., Zhang, T. and Ma, F. 2017. Sulphate sorption on rape (Brassica campestris L.) straw biochar, loess soil and a biocharsoil mixture. J. Environ. Manage., 201: 309-314.

Zheng, H., Wang, Z., Deng, X., Herbert, S. and Xin, B. 2013. Impact of adding biochar on nitrogen retention and bioavailability in agricultural soil. Geoderma, 206: 32-39. 